\title{
Evaluation of Pulmonary Function after Off- Pump Coronary Artery Bypass Graft Surgery with Thoracic Epidural Analgesia.
}

\author{
NC Mandal ${ }^{1}$, SAMA Sabur ${ }^{1}$, NAK Ahsan ${ }^{1}$, KK Karmakar ${ }^{2}$ \\ ${ }^{1}$ Department of Cardiac Surgery, NICVD, Dhaka. ${ }^{2}$ Department of Anaesthesiology, \\ NICVD, Dhaka.
}

\begin{abstract}
:
Key words:

Coronary artery

bypass graft

surgery; OPCAB,

Pulmonary

function,

Background: A substantial reduction of lung volumes and pulmonary function follows cardiac surgery. Pain may prevent effective breathing and coughing, as thoracic epidural analgesia may reduce post operative pain and improve early post operative pulmonary function. We tested the effect of thoracic epidural analgesia (TEA) on pulmonary function after off-pump coronary artery bypass (OPCAB) graft surgery.

thoracic epidural analgesia.

Methods: 60 patients undergoing off- pump coronary artery bypass (OPCAB) graft surgery were nonrandomized in to two groups. Group-I (30 patients) receiving thoracic epidural analgesia along with general anaesthesia $(G / A)$ but Group-II (30 patients) receiving general anaesthesia alone. Total ventilation

time, intensive care unit (ICU) stay, spirometric data, arterial blood gas (ABG) and X-ray chest (CXR) were recorded in postoperative follow-up period.

Results: Thirty patients were enrolled in each group. The demographics of the groups were similar. Patients in the epidural group had significantly less pain on the operative day and for the next 2 days.

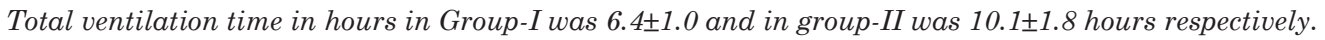
$F V C$ and $F E V_{1}$ were significantly different in group-I than group-II. On the postoperative period, ABG was done pre and postoperative period in both groups of patients. Significant differences was found in $\mathrm{pao}_{2}$ and paco $_{2}$, half an hour after extubation, $1^{\text {st }}$ postoperative day, $2^{\text {nd }}$ postoperative day $(p<0.05)$. Postoperative $C X R$ revealed significant pulmonary complication in group-II than group-I, higher in the epidural group on the first and second postoperative days. There were no complications related to epidural hematoma and no permanent neurologic squeal.
\end{abstract}

Conclusion: Thoracic epidural analgesia yields a slight, but significant improvement in pulmonary function most likely due to a more profound postoperative analgesia.

(Cardiovasc. j. 2013; 6(1): 31-36)

\section{Introduction:}

Coronary artery disease is the most common form of heart disease and the single most important cause of premature death in the developed world. ${ }^{1}$

Surgical management of Ischaemic heart disease (IHD) is coronary artery bypass graft surgery (CABG), which can be performed either under cardiopulmonary bypass (CPB) or by using offpump technique. Impairment of pulmonary function after CABG is one of the most common complications in the early post-operative period. ${ }^{2}$

Sternotomy, pleurotomy with opening of the pleural space, harvesting of internal mammary artery and pain may lead to deterioration of post- operative pulmonary function. In addition, the incidence of concurrent chronic lung disease is higher in the age group of patients who require revascularization of the myocardium. Combined these two factors indicate a need for documentation of pulmonary function pre-and postoperatively. ${ }^{3}$

Coronary revascularization procedure is done usually through median sternotomy incision and for this; impairment of pulmonary function is one of the most significant post-operative complication of $\mathrm{CABG}{ }^{4}$

For revascularization, emphasis is given over internal mammary artery (IMA) graft. The mediastinum and thoracic cavity are traumatized more with IMA than with reverse saphenous

Address correspondence: Dr. Naresh Chandra Mandal, Department of Vascular Surgery, National Institute of Cardiovascular Diseases, Dhaka, Bangladesh. E-mail: dr.ncm62@gmail.com.CC 
vein graft (RSVG) procedure. Indeed, some reports have found that IMA patients have worse pulmonary functions than the RSVG patients in the postoperative period. ${ }^{5}$

Basal atelectasis develops early during anaesthesia and may persist in the postoperative period. After surgery both respiratory muscles weakness and reduced, uncoordinated rib case expansion contribute to the restrictive ventilatory defect following median Sternotomy. Post-operative pain may cause hypo-ventilation and insufficient cough, leading to retention of airway secretions and aggravation of the impaired lung function. ${ }^{6}$

General Anaesthesia is the most commonly used anaesthetic technique and is considered the gold standard for $\mathrm{CABG}$, performed either on-pump or off-pump. Within the last few years, however, high thoracic epidural analgesia (TEA) as an adjunct to General Anaesthesia has become more prevalent and has been shown to have potentially benefited in patients with coronary artery disease. Potential advantage of TEA include thoracic sympathicolysis with subsequent improvement of coronary perfusion, decrease heart rate, decrease endogenous stress response and reduced risk for pre-operative myocardial ischemia . Furthermore improved post-operative pulmonary function, additionally post-operative pain management is facilitated by continuous epidural application of analgesia; such effective pain management improves early post-operative mobilization \& recovery. ${ }^{7}$

The epidural analgesia is an important adjunct to immediate extubation because the intraoperative anesthesia requirements are less and analgesia optimized. The potential benefits of early extubation include cost savings, lowered nursing dependency, reduced airway and lung trauma, improved cardiac output and renal perfusion with spontaneous respiration. ${ }^{8}$

Pulmonary function is preserved in patients receiving TEA, probably as a result of several factors, which include superior analgesia (allowing the patient to cooperate more fully with physiotherapy), the avoidance of parenteral opoids and their mood altering effects , and the inhibition of bulbosplanchnic afferent nerve fibers. Maximal inspiratory lung volumes are approximately $30 \%$ larger in patients receiving TEA. Patients receiving TEA have $250-300 \mathrm{ml}$ of reserve lung volume. This volume increases the respiratory reserve and decreases the incidence or duration of atelectasis or pulmonary infection. ${ }^{9}$

It has been found in several studies that pulmonary function is better preserved in offpump coronary artery bypass surgery are with TEA adjunct to GA than GA alone.

In our country, no study has yet been performed. This study was undertaken to see the postoperative lung function after off-pump coronary artery bypass graft surgery with or without thoracic epidural analgesia

\section{Methods:}

Patients:

60 patients who were undergoing elective Offpump Coronary Artery Bypass Graft Surgery were randomized to receive Thoracic Epidural Analgesia \& G/A in group-I(30 patients) and only G/A in group-II (30 patients).Patients associated with with valvular diseases, congenital cardiac anomaly, urgent CABG and re-exploration, associated other systemic (eg. hepatic, renal, chronic pulmonary) dysfunction were excluded from the study.

Demographic data, clinical parameter including risk factor for CAD were noted. Pulmonary function was done in pre and post operative periods.

\section{Procedure and effect of Thoracic Epidural Analgesia:}

All patients were premedicated Tab. Lorazepam $1 \mathrm{mg}$ at bed time day before operation. On the arrival in the operation theater, intravenous cannulation and direct blood pressure monitoring using radial arterial catheterization was established in both groups. In the group-I (study group), a side holed multiport epidural catheter was inserted at the level of T1-2 or T2-3 interspaces in the morning on the day of surgery under local anesthesia using midline approach at right lateral decubitus position with the loss of resistance or hanging drop technique. The catheter was directed cephaled and advanced 3- 
$4 \mathrm{~cm}$ into the epidural space. The initial bolus dose of $0.25 \%$ bupivacaine $10 \mathrm{ml} 15 \mathrm{~min}$ before surgery was given through epidural catheter followed by continuous epidural infusion with $0.25 \%$ bupivacaine will be maintained during operation at $8 \mathrm{ml} / \mathrm{hr}$ and post-operatively will be continued at 3-4 ml/hr up to 72 hours. Sensory block was determined bilaterally using loss of warm-cold sensation as well pinprick discrimination. In both groups general anaesthesia was induced with fentanyl 10 microgram $/ \mathrm{kg}$ IV and with propofol $1.5 \mathrm{mg} / \mathrm{kg} \mathrm{IV}$.

Statistical Analysis: Data were collected by personal interview and hospital records. The collected data were complied and a data file was constructed. This data were analyzed by unpaired student $t$ test and Chi square test $\left(\mathrm{X}^{2}\right)$ using SPSS (Statistical Program for Social Science). The analyze data were presented by crossing of variables in the form of tables and graph etc. A $\mathrm{p}$ value equal to or less than 0.05 was considered significant.

\section{Results:}

Demographic profile of both groups are shown in the table (I, II \& III) which reveals there was no significant difference in terms of age, sex \& total operation time in both study group \& control group.

Table -I

Age distribution of the patients between groups

\begin{tabular}{|c|c|c|c|c|c|}
\hline \multirow[t]{2}{*}{ Age in years } & \multicolumn{2}{|c|}{ Group I } & \multicolumn{2}{|c|}{ Group II } & \multirow[t]{2}{*}{$\mathrm{P}$ value } \\
\hline & $\mathrm{n}$ & $\%$ & $\mathrm{n}$ & $\%$ & \\
\hline $40-50$ & 11 & 40.0 & 15 & 50.0 & \\
\hline $51-60$ & 10 & 30.0 & 9 & 30.0 & \\
\hline$>60$ & 9 & 30.0 & 6 & 20.0 & \\
\hline Total & 30 & 100 & 30 & 100 & \\
\hline Mean \pm SD & \multicolumn{2}{|c|}{$52.6 \pm 8.6$} & \multicolumn{2}{|c|}{$53.3 \pm 6.6$} & 0.724 \\
\hline
\end{tabular}

Total 60 patients were included in this study, 30 in Group-I who underwent OPCAB with GA and TEA and the rest 30 were Group-II who underwent OPCAB with GA only. The mean age in group-I was 52.6 \pm 8.6 and that of in GroupII was $53.3 \pm 6.6$ years respectively. The mean age difference was not statistically significant $(\mathrm{P}>0.05)$.
Table-II

Sex distribution of the patients between groups

\begin{tabular}{lccccccc}
\hline & & & \multicolumn{2}{c}{ Group I } & \multicolumn{2}{c}{ Group II } & P value \\
Sex & & & $\mathrm{n}$ & $\%$ & $\mathrm{n}$ & $\%$ & \\
\hline Male & 55 & $91.66 \%$ & 27 & 90.00 & 28 & 93.33 & \\
Female & 5 & $8.33 \%$ & 3 & 10.00 & 2 & 6.66 & 0.500 \\
\hline Total & 60 & $100 \%$ & 30 & 100.0 & 30 & 100.0 & \\
\hline
\end{tabular}

Among 60 patients, in group-I 27(90.00\%) patients were male and $3(10.00 \%)$ were female, and in group-II 28(93.33\%) were male and 2 $(6.66 \%)$ were female patients. Male female ratio is 11:1. Male female difference was not statistically significant $(\mathrm{P}>0.05)$ in Chi square test.

Table-III

Total Operation Time

$\overline{\text { Operation time Group I Group II P value }}$ (minute)

\begin{tabular}{lll}
\hline Mean \pm SD & $291.0 \pm 18.0291 .5 \pm 15.6$ & 0.903 \\
\hline
\end{tabular}

Total operation time in group-I was $291.0 \pm 18.0$ minutes and in group-II was $291.5 \pm 15.6$ minutes. There was no significant differences were found statistically in between groups.

Table-IV

Total ventilation time in hours

\begin{tabular}{|c|c|c|c|c|c|}
\hline \multirow{2}{*}{$\begin{array}{l}\text { Ventilation time } \\
\text { (hours) }\end{array}$} & \multicolumn{2}{|c|}{ e Group I } & \multicolumn{2}{|c|}{ Group II } & \multirow{2}{*}{$\mathrm{P}$ value } \\
\hline & $\mathrm{n}$ & $\%$ & $\mathrm{n}$ & $\%$ & \\
\hline$<6$ hours & 6 & 20.0 & 3 & 10.0 & \\
\hline $6-12$ & 24 & 80.0 & 27 & 90.0 & \\
\hline Total & 30 & 100.0 & 30 & 100.0 & \\
\hline Mean \pm SD & \multicolumn{2}{|c|}{$6.4 \pm 1.0$} & \multicolumn{2}{|c|}{$10.1 \pm 1.8$} & 0.001 \\
\hline
\end{tabular}

Total ventilation time in group-I was $6.4 \pm 1.0$ hours and in group-II was $10.1 \pm 1.8$ hours respectively which was statistically significant $(p<0.05)$.

Table-V

Total ICU Stay in hours

\begin{tabular}{lccccr}
\hline $\begin{array}{l}\text { ICU stay } \\
\text { (hours) }\end{array}$ & \multicolumn{2}{c}{ Group I } & \multicolumn{2}{c}{ Group II } & P value \\
\hline $39-48$ & 27 & 90.0 & 3 & 10.0 & \\
$>48$ & 3 & 10.0 & 27 & 900 & 0.001 \\
Total & 30 & 100.0 & 30 & 100.0 & \\
Mean \pm SD & $43.4 \pm 3.0$ & $52.9 \pm 5.0$ & 0.001 \\
Range (Min, Max) & $(40-50)$ & $(39-59)$ & \\
\hline
\end{tabular}


Table shows that mean value of total ICU stay in group-I was $43.4 \pm 3.0$ hours and in group-II was $52.9 \pm 5.0$ hours, which was statistically significant $(\mathrm{p}<0.05)$.

Table -VI

Lung Function test by spirometry in between groups

\begin{tabular}{lccc}
\hline & Mean \pm SD & Mean \pm SD & p-value \\
\hline FVC (L/min) & & & \\
Pre-operative & $3.08 \pm 0.3$ & $3.21 \pm 0.3$ & 0.083 \\
th POD & $1.95 \pm 0.3$ & $1.81 \pm 0.2$ & 0.037 \\
One month & $2.28 \pm 0.4$ & $2.05 \pm 0.3$ & 0.016 \\
Two months & $2.53 \pm 0.2$ & $2.54 \pm 0.4$ & 0.903 \\
Three months & $2.62 \pm 0.3$ & $2.58 \pm 0.3$ & 0.607 \\
FEV $(\mathrm{L} /$ min) & & & \\
Pre-operative & $2.46 \pm 0.5$ & $2.56 \pm 0.3$ & 0.353 \\
th POD & $1.56 \pm 0.3$ & $1.44 \pm 0.2$ & 0.001 \\
One month & $1.82 \pm 0.3$ & $1.64 \pm 0.2$ & 0.008 \\
Two months & $2.02 \pm 0.2$ & $2.03 \pm 0.4$ & 0.903 \\
Three months & $2.09 \pm 0.3$ & $2.06 \pm 0.3$ & 0.692 \\
FEV $/$ FVC (\%) & & & \\
Pre-operative & $79.8 \pm 15.2$ & $79.75 \pm 4.3$ & 0.955 \\
th POD & $80.0 \pm 4.0$ & $79.55 \pm 3.2$ & 0.632 \\
One month & $79.7 \pm 1.9$ & $80.00 \pm 5.8$ & 0.492 \\
Two months & $79.8 \pm 2.7$ & $79.92 \pm 3.7$ & 0.924 \\
Three months & $79.7 \pm 4.0$ & $79.84 \pm 5.8$ & 0.962 \\
\hline
\end{tabular}

Table-VII

$A B G$ results in both groups of study population

\begin{tabular}{|c|c|c|c|}
\hline$\overline{\mathrm{ABG}}$ & $\begin{array}{r}\text { Group I } \\
\text { Mean } \pm \text { SD }\end{array}$ & $\begin{array}{r}\text { Group II } \\
\text { Mean } \pm \text { SD }\end{array}$ & $\mathrm{P}$ value \\
\hline \multicolumn{4}{|l|}{$\overline{\mathrm{PaO}_{2}}$} \\
\hline Pre-operative & $134.23 \pm 4.89$ & $133.67 \pm 4.4$ & $0.644^{\mathrm{ns}}$ \\
\hline On arrival at ICU & $286.64 \pm 22.4$ & $276.23 \pm 20.7$ & $0.062^{\mathrm{ns}}$ \\
\hline Half hr.before & & & $0.081^{\mathrm{ns}}$ \\
\hline extubation & $206.51 \pm 18.6$ & $199.25 \pm 12.3$ & \\
\hline Half hr.after & & & $0.020^{\mathrm{s}}$ \\
\hline extubation & $128.87 \pm 3.8$ & $126.69 \pm 3.1$ & \\
\hline $1^{\text {st }}$ POD & $130.21 \pm 3.5$ & $128.27 \pm 3.1$ & $0.028^{\mathrm{S}}$ \\
\hline $2^{\text {nd }}$ POD & $132.47 \pm 5.4$ & $129.16 \pm 6.4$ & $0.037^{\mathrm{s}}$ \\
\hline $6^{\text {th }}$ POD & $133.23 \pm 5.9$ & $133.11 \pm 5.3$ & $0.935^{\text {ns }}$ \\
\hline \multicolumn{4}{|l|}{$\mathrm{PaCO}_{2}$} \\
\hline Pre-operative & $38.46 \pm 1.7$ & $38.96 \pm 1.8$ & $0.276^{\mathrm{ns}}$ \\
\hline On arrival at ICU & $40.28 \pm 1.8$ & $40.32 \pm 1.9$ & $0.938^{\mathrm{ns}}$ \\
\hline Half hr.before & & & $0.772^{\mathrm{ns}}$ \\
\hline extubation & $40.13 \pm 0.6$ & $40.25 \pm 1.5$ & \\
\hline Half hr.after & & & $0.001^{\mathrm{S}}$ \\
\hline extubation & $41.24 \pm 1.9$ & $45.13 \pm 1.7$ & \\
\hline $1^{\text {st }}$ POD & $40.13 \pm 1.6$ & $46.25 \pm 1.5$ & $0.001^{\mathrm{S}}$ \\
\hline $2^{\text {nd }}$ POD & $39.27 \pm 1.8$ & $38.43 \pm 1.7$ & $0.055^{\mathrm{ns}}$ \\
\hline $6^{\text {th }}$ POD & $36.39 \pm 1.8$ & $37.27 \pm 1.7$ & $0.058^{\mathrm{ns}}$ \\
\hline \multicolumn{4}{|l|}{$\mathrm{SPO}_{2}$} \\
\hline Pre-operative & $99.1 \pm 0.6$ & $98.9 \pm 0.5$ & $0.693^{\mathrm{ns}}$ \\
\hline On arrival at ICU & $99.2 \pm 0.9$ & $98.9 \pm 0.7$ & $0.721^{\mathrm{ns}}$ \\
\hline Half hr.before & & & \\
\hline extubation & $99.2 \pm 0.6$ & $98.9 \pm 0.8$ & $0.532^{\mathrm{ns}}$ \\
\hline Half hr.after & & & \\
\hline extubation & $98.9 \pm 0.7$ & $98.9 \pm 0.7$ & $0.761^{\mathrm{ns}}$ \\
\hline $1^{\text {st }} \mathrm{POD}$ & $99.1 \pm 0.8$ & $98.9 \pm 0.9$ & $0.566^{\mathrm{ns}}$ \\
\hline $2^{\mathrm{nd}} \mathrm{POD}$ & $99.2 \pm 0.5$ & $98.9 \pm 0.7$ & $0.663^{\mathrm{ns}}$ \\
\hline $6^{\text {th }}$ POD & $99.2 \pm 0.6$ & $98.3 \pm 0.5$ & $0.510^{\mathrm{ns}}$ \\
\hline
\end{tabular}

$\mathrm{p}$ value reached from unpaired-test
This table shows the spirometry results of two groups of patients during their whole study period. The results of FVC and FEV1 in the preoperative period, two months and three months follow-up period were found not significant but in the $7^{\text {th }}$ Post operative day and first month follow-up FVC and FEV1 were found statistically significant in between groups $(p<0.05)$. FEV1/FVC ratio was not statistically significant all over the study period in between groups.

This table has shown that $\mathrm{PaO}_{2}$ on preoperative period, On arrival at ICU, half an hour before extubation and in $6^{\text {th }}$ Post-operative day was found statistically not significant in both group. But half an hour after extubation, $1^{\text {st }}$ Postoperative day and $2^{\text {nd }}$ Postoperative day $\mathrm{PaO}_{2}$ was found statistically significant in both groups. $\mathrm{PaCO}_{2}$ on preoperative period, on arrival at ICU, half an hour before extubation, $2^{\text {nd }}$ post-operative and in $6^{\text {th }}$ Post-operative day was found statistically not significant in both group but half an hour after extubation and $1^{\text {st }}$ Post-operative day it was found statistically significant in both group and $\mathrm{SPO}_{2}$ was found statically not significant all over the study period in both study group.

Table-VIII

$X$-Ray Chest $P / A$ view in both groups of patients

\begin{tabular}{lccc}
\hline Variables & Group I & Group II & P Value \\
\hline Pre Op. CXR & & & \\
Normal & 30 & 30 & \\
Abnormal & 00 & 00 & \\
Post operative & follow-up CXR & & \\
Normal & 29 & 23 & 0.026 \\
Abnormal & 1 & 7 & \\
\hline
\end{tabular}

$\mathrm{p}$ value reached from chi square test

Group I : Off-pump CABG patients with TEA

Group I I: Off-pump CABG patients without TEA

This table shows X-ray chest P/A view of both group of patients in preoperative period and was found not statistically significant. But on the Post-operative follow-up periods there were significant difference found in both group of patients. 
Table-IX

Total Hospital Stay in Days

\begin{tabular}{|c|c|c|c|c|c|}
\hline \multirow[b]{2}{*}{$\begin{array}{l}\text { Post operative } \\
\text { hospital stay } \\
\text { (days) }\end{array}$} & \multicolumn{2}{|c|}{ Group I } & \multicolumn{2}{|c|}{ GroupII } & \multirow[t]{2}{*}{$\mathrm{P}$ value } \\
\hline & $\mathrm{n}$ & $\%$ & $\mathrm{n}$ & $\%$ & \\
\hline $6-10$ & 27 & 90.0 & 5 & 16.66 & \\
\hline $11-15$ & 3 & 10.0 & 25 & 83.33 & 0.001 \\
\hline Total & 30 & 100.0 & 30 & 100.0 & \\
\hline Mean \pm SD & 8.7 & \pm 1.8 & 11.7 & \pm 2.7 & 0.001 \\
\hline Range (Min, Max) & $(6$ & $-12)$ & $(6$ & $-15)$ & \\
\hline
\end{tabular}

This table shows the total hospital stay in days in both group of patient. The mean values are $8.7 \pm 1.8$ days in group I and $11.7 \pm 2.7$ days in group II respectively. There was found statistically significant differences in respect to hospital stays in two groups $(\mathrm{p}<0.05)$.

\section{Table-X}

Post Operative pulmonary complications within 3 months

\begin{tabular}{lccccc}
\hline & \multicolumn{2}{c}{ Group I } & \multicolumn{2}{c}{ Group II } & P value \\
Variables & $\mathrm{n}$ & $\%$ & $\mathrm{n}$ & $\%$ & \\
\hline Pleural Effusion & 1 & 3.33 & 2 & 6.66 & \\
Pneumothorax & 0 & 0.0 & 1 & 3.33 & \\
Atelectasis & 0 & 0.0 & 4 & 13.32 & \\
\hline Total & 1 & & 7 & & 0.026 \\
\hline
\end{tabular}

This table shows early post operative pulmonary complications in both study groups of patients. These are Pleural effusion, pneumothorax and atelectasis. There was only one patient in groupI with pleural effusion. But in group-II, two patients were with pleural effusion, one patient with pneumothorax and four patients with atelectasis were found. There was statistically significant differences in both group of patients $(\mathrm{p}<0.05)$.

\section{Discussion:}

The patients in both groups of this study are similar and comparable as per as demographic and base line clinical parameters. The mean age was $52.6 \pm 8.6$ years in epidural group and $53.3 \pm 6.6$ years in control group. Stenseth et al series showed that the mean age was $54.6 \pm 1.6$ years in epidural group and $55.8 \pm 1.2$ years in control group that was nearly comparable with our findings. ${ }^{6}$

Preoperative pulmonary functions were similar in both groups. The total mechanical ventilation time and ICU stay in hours was observed in both groups of patients. The mean value of ventilation time in hours in group-I was $6.4 \pm 1.0$ and in groupII was $10.1 \pm 1.8$ hours. The mean value of total ICU stay in hours in group-I was $43.4 \pm 3.0$ and in group-II was $52.9 \pm 5.0$ hours. In statistical analysis significant difference was found in two groups in respect to mechanical ventilation time and ICU stay in hours. Study done by Bakhtiary et al and Tenling et al support this result. 7,10

Preoperative anf postoperative Spirometry was done in both groups of patients to compare pulmonary function between the two groups. FVC and FEV1 were found significantly different in group-I than group-II, on seventh post operative day and one month follow up period, which was similar to the study done by Stenseth et al. ${ }^{6}$

Arterial blood gas (ABG) was analyzed in both groups of patients preoperatively, on arrival at ICU, half an hour before extubation, half an hour after extubation and in the 1st POD, 2nd POD and the 6th Post-operative day. Significant difference was found in $\mathrm{PaO} 2$ and $\mathrm{PaCO} 2$ half an hour after extubation, 1st Post-operative day and 2nd Postoperative day. These findings were closely resembles the findings of Bakhtiary et al. and Tenling et al. 7,10

Post operative hospital stay in days in both groups of patients was observed. There was statistically significant differences in respect to hospital stay in days between groups. Post operative CXR revealed significant pulmonary complication like pleural effusion, pneumothorax and atelectasis occurred in group-II, which was statistically significant and was similar to the study done by Tenenbein et al. ${ }^{11}$

Study limitations: There are a number of limitations with our data \& results.

1. All operations were not performed by the same surgeon.

2. Patients were not randomly selected.

3. Sample size was small.

4. Long term follow-up was not given. 


\section{Conclusion:}

It can be concluded that Thoracic Epidural Analgesia (TEA) in combination with General Anaesthesia (GA) in Off-pump Coronary Artery Bypass (OPCAB) graft surgery is a safe procedure, which may lead to a better pain relief and improve the ability to cough by a greater expiratory muscular strength as well as better preservation of post-operative pulmonary function.

\section{Conflict of Interest - None.}

\section{References:}

1. Newby DE, Grubb NR, Bradbury A. Cardiovascular disease. In: Colledge NR, Walker BR, Ralston SH. Eds. Davidson's Principles and Practice of Medicine. UK: Churchill Livingstone, 2010 : 521-640.

2. Asimakopoulos G, Smith PLC, Ratnatunga CP, Taylor KM. Lung injury and acute respiratory disress syndrome after cardiopulmonary bypass. Ann Thorac Sug 1999; 68: 1107-1115.

3. Hossain MZ, Evaluation of pulmonary function after coronary artery bypass graft surgery, MS thesis, Dhaka University, Dhaka, 2004.

4. Vargas FS, Torra-Filho M, Huch W, Teixeira LR, Cukier A, Light RW. Pulmonary Function after coronary artery surgery. Respir Med 1997; 91: 629-633.

5. Jenkin SC, Soutar SA, Forsyth A, Keaters J RW, Moxhan J. Lung Function After Coronary Artery Surgery using the internal mammary artery and the saphenous vein. Thorac 1989; 44: 209-211.

6. Stenseth R, Bjella L, Berg EM, Christensen O, Levang OW, Gisvold SE. Effects of thoracic epidural analgesia on pulmonary function after coronary artery bypass surgery. Eur J Cardio-Thorac 1996; 10: 859-865.

7. Bakhitary F, Therapidis P, Dzemali O, Koray Ak, Ackermann H, Meininger D, Kessler P, Kleine P, Moritz A, Aybek T. Dogan S. Impact of high thoracic epidural anesthesia on incidence of Perioperative atrial fibrillation in off- pump coronary bypass grafting. Journal of Thoracic and Cardiovascular Surgery 2007; 134: 460-464.

8. Royse CF, Royse AG, Soeding PF. Routine Immediate Extubation After Cardiac Operation. Ann Thorac Surg 1999; 68: 1326-1329.

9. Kessler P, Aybek T, Neidhast G, Dogan S, Lischke V, Bremerich DH, Byhahn C. Comparison of Three Anesthetic Techniques for Off-pump Coronary Artery Bypass Grafting: General Anesthesia, Combined General and High Thoracic Epidural Anesthesia or High Thoracic Epidural Anesthesia Alone. J Cardiothor Vasc An 2005; 19: 32-39.

10. Tenling P, Joachimsson PO, Tyden H, Wegenius G, Hedenstierna G. Thoracic Epidural Anesthesia as an Adjunct to General Anesthesia for Cardiac Surgery: Effects on Ventilation- Perfusion Relationships. J Cardiothor Vasc An 1999; 13: 258-264.

11. Tenenbein PK, Debrouwere R, Maguire D, Duke PC, Kowalski SE. Thoracic Epidural Analgesia Improves Postoperative Pulmonary Function in Patients Undergoing Coronary Artery Bypass Graft Surgery. Anesthesiology 2004;101: 207-212. 